\title{
Pumped Storage Power Plants: The Treasure of Renewable Energy Sector in India
}

\author{
N.Subhashini ${ }^{a}$, Dr.R.M.Sasiraja ${ }^{b}$ \\ aAssistant Professor Department of Electrical Engineering, Sri Krishna College of Engineering, Coimbatore, India., \\ subhashininesam@gmail.com \\ ${ }^{\mathbf{b}}$ Associate Professor, Department of Electrical Engineering, Sethu Institute of Technology, Virudhunagar, India. \\ rmsasiraja@gmail.com
}

Article History: Received: 10 November 2020; Revised 12 January 2021 Accepted: 27 January 2021; Published online: 5 April 2021

\begin{abstract}
Renewable Energy has become an inevitable one in the world of power sector. Especially country like India (the second largest populated) powering the entire nation is not an easy thing. Typically we depend upon conventional energy sources which is to be dissipate at any point of time. Therefore now we are returning back to the pavilion, started using non conventional energy sources like our ancestors. Unlike conventional sources, the nonconventional sources are profuse in nature. These sources will be even more effective when coordination comes into picture. Mostly coordination will be done with wind and solar predominantly. In this paper, we are to reveal about the hidden treasure, the pumped storage power plant (PSP) its advantages and disadvantages.
\end{abstract}

Keywords: Coordination, Pumped storage Power Plant, Hybrid Technology.

\section{Introduction}

Civilization depends on energy. Improvement are based on the amount of energy used. A large increase in energy consumption was noted especially after the Second World War. Conventional energy sources provide more than $90 \%$ of the overall quantity of energy. Furthermore demand is growing day by day and the conventional energy sources is of limited amount. The last decades have witnessed the utilization of renewable energy sources in a large scale. It is a fact that all energy sources are connected- one way or the other- to the Sun. The Sun's energy is converted into many ways by these energy sources. The primary energy flow, however, is not constant. It depends on climatic conditions Energy demand is not constant either. Therefore the need for a storage system is mandatory in nature. Initially, the energy storage problem was sort out by of wood or by damming springs. Later, coal became the most important energy source. Today there are many forms of energy storage, petrol tank is the convenient of all. Technically the storage of oil is not difficult and the time storage depends on when the tap of the tank will turn off. Storage can be maintained for a prolonged time without any loss. Recently, renewable energy sources have attracted considerable interest. However, most renewable sources do not provide a continual energy supply and cannot be directly stored, as a result they require secondary storage systems. Electrical power systems are the most flexible and convenient energy carriers from producers to consumers. The main disadvantage of electricity as an energy carrier is the impossibility of storing it. The problem of energy storage becomes more and more crucial as the development of the power systems leads to an increase of their capacity. In an electricity power system, which is based on thermal, nuclear and renewable generation, the storage procedure has a wide field of application. As renewable energies are replacing the fossil fuels, the demand for storing energies arises. The power network storage can provide a lot of benefits in different areas, thus balancing the demand over a long period of time and allows extensive use of renewable energy sources. System control arising from random generators (such as wind) can be mitigated with a storage system and therefore the proportion of renewable generation can be increased on the network. Conventional units, which are used as auxiliary units, could be replaced by energy storage. Power plants, which operate with constant energy supply, could be combined with energy storage to provide energy at peak times.

\section{Renewable Energy Sources In India}

\section{A. Renewable energy sources in India}

As nations contend with the increasingly devastating impact of climate change, largely caused by anthropocentric developmental activities, the role of renewable energy in the energy and electricity mix becomes primary. Across the world, many of the developed and developing countries have started giving primacy to rapidly increase the percentage of renewable energy in the overall energy mix of their economies. Renewable Energy has become one of the most important factors and hope for the world to 
preservethepristineenvironmentandtheplanet'sresourcesforfuturegenerations.Indiahasbeenleading the world on this front showing the developing nations of the world a way forward for socio-economic growth without degradation of theenvironment. Indiaisstrivinginitstargetsforpromotingrenewableenergy.InIndia,renewableenergyhasstarted playinganimportantroleintheexpansionofgridpower,providingenergyaccess,reducing theconsumptionoffossilfuelsandhelpingIndiapursueits

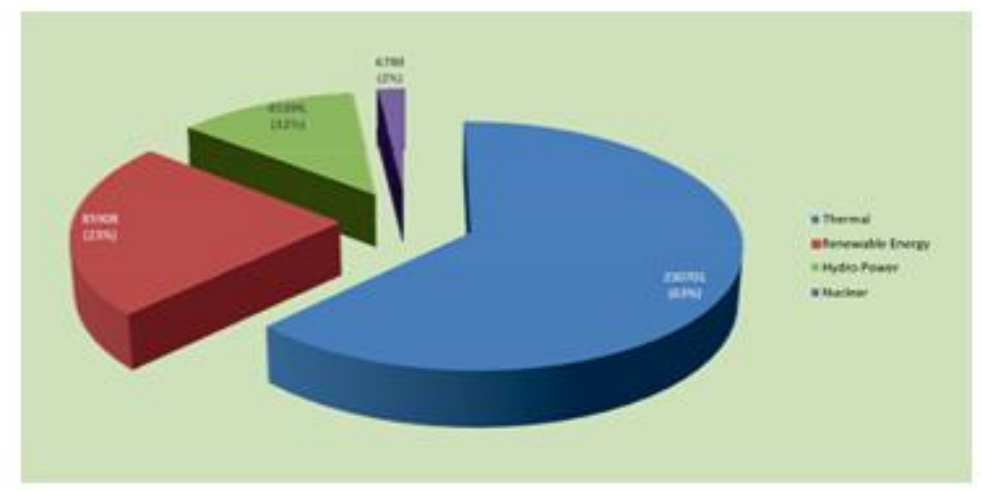

Figure 1.1: India - Source Wise Installed Power Generation Capacity (MW) as on 31.12.2019

Low carbon developmentpath. India is planning to construct $175 \mathrm{GW}$ of renewable capacity by 2022 to increase the total installed $\begin{array}{llllll}\text { capacity by } & 40 & \text { by } & 2030 . & \text { Duringtheyear2019- }\end{array}$ 20atotalof7,591.99MWrenewableenergycapacityhasbeenaddedinthecountry till 31.12.2019. India has a vast nonconventional energy sources of which wind is of $300 \mathrm{GW}$, solar is of $750 \mathrm{MW}$ and small hydro is of $20 \mathrm{GW}$ and bio-energy potential of $25 \mathrm{GW}$. Further, there exists significant potential from decentralized applications for meeting the hot water requirement for residential, commercial and industrial sector throughsolarenergyandalsomeetingcookingenergyneedsintheruralareasthroughbiogas.Renewable energy also has the potential to usher in universal energy access. In December 2019, the cumulative renewable power installed capacity was $84.84 \mathrm{GW}$. Capacityaddition of $7.59 \mathrm{GW}$ has been achieved during the current year 2019-20 (upto31.12.2019)

\section{B. Wind Energy}

India's wind energy sector shows a reliable progress which is led by indigenous wind power industry. The operation capability has been increased due to the expansion of the wind industry. The country currently has the fourth highest wind installedcapacityintheworldwithtotalinstalledcapacityof

Table 1: India - Source Wise Installed Power Generation Capacity (MW) as on 31.12.2019

\begin{tabular}{|c|c|c|}
\hline Sector & $\begin{array}{c}\text { Achievement } \\
\text { (April-Dec 2019) }\end{array}$ & $\begin{array}{c}\text { Cumulative } \\
\text { Achievements (on } \\
\text { 31.12.2019) }\end{array}$ \\
\hline Wind Power & 1879.21 & 37505.18 \\
\hline Solar Power - Ground Mounted & 5013.00 & 31379.30 \\
\hline Solar Power - Roof Top & 536.88 & 2333.23 \\
\hline Small Hydro Power & 78.40 & 4671.55 \\
\hline $\begin{array}{c}\text { Bio Power (Biomass \& } \\
\text { Gasification and } \\
\text { Bagasse Cogeneration) }\end{array}$ & 83.00 & 9861.31 \\
\hline Waste to Power & 1.50 & 139.80 \\
\hline Total & $\mathbf{7 5 9 1 . 9 9}$ & $\mathbf{8 5 9 0 8 . 3 7}$ \\
\hline
\end{tabular}

37.50GW(ason31stDecember,2019)and 62.036 Billion Units were generated from wind power during 201819.Wind is an intermittent and site-specific source of energy and therefore, an extensive Wind Resource Assessment is essential for the selection of potential sites. 
Table 2: State Wise Installed Wind Power Generation Capacity (MW)

\begin{tabular}{|c|c|c|}
\hline S. No. & State & Wind Power (MW) \\
\hline 1 & Andhra Pradesh & 4092.450 \\
\hline 2 & Gujarat & 7359.220 \\
\hline 3 & Karnataka & 4753.400 \\
\hline 9 & Kerala & 62.500 \\
\hline 4 & Madhya Pradesh & 2519.890 \\
\hline 5 & Maharashtra & 5000.330 \\
\hline 6 & Rajasthan & 4299.720 \\
\hline 7 & Tamil Nadu & 9285.265 \\
\hline 9 & Telangana & 128.100 \\
\hline 10 & Others & 4.300 \\
\hline & Total (MW) & $\mathbf{3 7 5 0 5 . 1 7 5}$ \\
\hline
\end{tabular}

800 wind-monitoring stations has been installed by National Institute of Wind Energy (NIWE) all over India.The latest

assessment indicatesgrosswindpowerpotentialof302.25GWand695.50inthecountryat100meterand120meter respectively, abovegroundlevel.The installed capacity of grid-interactive wind power in the country as on 31.12.2019 is 37.50 GW and state-wise installed capacity (in MW) is shown in Table2.

\section{Solar Energy}

Solar energy is the everlasting energy resource on earth and it can be used in either direct (solar radiation) or indirect (wind, biomass, hydro, ocean, etc.) forms. Solar energy can be used for water heating, cooking, Drying, water purification, power generation and it is converted into electricity, which can then be used for a number of purposes such as lighting, pumping, communications and power supply in electrified areas.

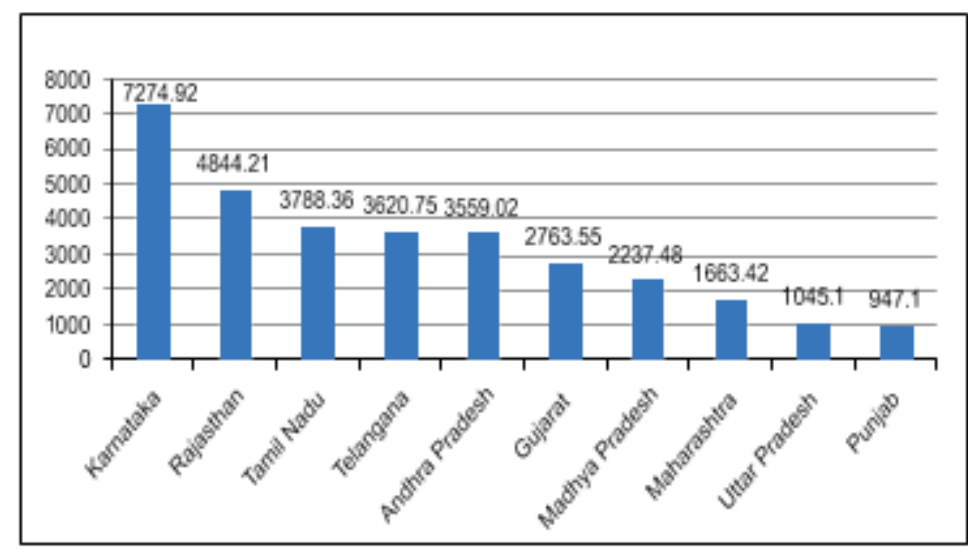

Figure 3: Top 10 States in Solar Installation (capacity in MW as on 31-12-2019)

The total annual solar radiation falling on the earth is more than 7500 times the world's total annual primary energy consumption. The annual solar radiation reaching the earth's surface, is an order of magnitude greater than all the estimated non-renewable energy resources, including fossil fuels and nuclear. However, majority of the worldwide energy use is based on fossil fuels.Depending on the location, the daily incidence ranges from 4 to 7 $\mathrm{kWh} / \mathrm{m} 2$, with the hours of sunshine ranging from 2300 to 3200 per year. The MNRE, is working with the Indian Renewable Energy Development Agency (IREDA) to encourage the use of solar power to increase the share of renewable energy in the Indian market. This promotion is being achieved through $R \& D$, demonstration projects, government subsidy programs, and also private sector projects.

\section{D.Pumped Storage Power Plant}

A pumped storage plant (PSP) consist of upper reservoir and lower reservoir, during high load condition the water flows from upper reservoir to lower reservoir to produce electric power, during off-load conditions the 
excess power is used to pump water back to the upper reservoir which is used for load balancing. The PSP runs on low cost, off-peak period thus generating higher revenue by selling more electricity during periods of peak demand, when electricity prices are the highest. PSPs allow excess energy from both conventional and nonconventional sources to store power, so that excess power can be used on high demand period. PSPs can easily respond to sudden changes in electrical demand whereas conventional energies cannot make sudden response. Along with energy management, PSPs help control electrical network frequency and provide reserve generation. PSPs are economical because they flatten out load variations in the grid and also help in coordinating large groups of heterogeneous generators. The round-trip energy efficiency of PSPs varies in practice between 70 per cent and 80 per cent and it is the most cost-effective means of storing large amounts of electrical energy.

\section{Status OfPsp Development}

The strange fact is that need for developing pumped storage was realised as early as in 1960. The first PSP, of capacity $700 \mathrm{MW}$, was built at the NagarjunaSagar dam in Telengana in 1980. Till now 4804 MW capacity of 11 PSP have been installed of which only 7 PSPs are working in pumped mode. As per Table 4, this is only the few PSPs installed out of 96,000 MW potentials identified by CEA in different parts of India. Region-wise, the western region has the highest PSP potential at 39,684 MW due to the topographical features with steep gradients of rivers originating from the Western Ghats. As per CEA data on under construction PSP projects (as of December 2019), three projects are under way - the 1,000 MW Tehri Stage II project in Uttarakhand, which is likely to be commissioned in 2021-23; the Koyna Left Bank (80 MW) in Maharashtra being implemented by the Water Resources Department of Maharashtra; and the Kundah Pump Storage project Stages I, II, III and IV (500 MW) in Tamil Nadu being implemented by TANGEDCO. The Kundah project is likely to be commissioned by 2022-23. The Tehri project by THDC Limited will be the first PSP under the central sector. Seven projects of $6120 \mathrm{MW}$ capacity are under survey and investigation, is in progress. These projects are Upper Indravati (Odisha, 600MW), Upper Kolab (Odisha, 320MW), Sharavathy (Karnataka, 2,000 MW), Balimela (Odisha, 500MW), Kodayar (Tamil Nadu, 500 MW), Pinnapuram (Andhra Pradesh, 1,200 MW) and Sillahalla Stage I (Tamil Nadu, 1,000 MW). The detailed project report has been approved by the CEA for the Turga project (4X250 MW) in West Bengal and construction is expected to start shortly. West Bengal has been a frontier in the promotion of pumped storage. Its 900 MW Purulia project, set up in 2007, is running successfully. The company has planned a 1,000 MW PSP project in Turga and it is expected to be commissioned by May 2027.

\section{A.Benefits of PSP}

Pumped storage can provide additional grid services such as reserve generation and network frequency control. PSP allows pumping at less load, thus increasing the flexibility to integrate a PSP with wind/ solar energy. A PSP with a reasonable small reservoir in the upstream and downstream is large enough to produce ample amount of power during peak demand periods. New approaches are suggested for developing pumped storage projects is to locate the reservoirs in areas that are physically separated from the existing river systems. These projects are termed as "closed-loop" pumped storage because they have minimal to no impact on the existing river systems. After the initial filling of the reservoirs, the only additional water requirement is the make-up water required to offset evaporation. By avoiding the existing complex aquatic systems entirely, these types of projects can greatly reduce the most significant aquatic impacts associated with project development. Pumped hydro has a high service life (of more than 50 years) and is flexible and fast acting, which can improve the uptake of this technology. Given the government's large renewable energy capacity addition program for the year 2022, pumped storage plants can play a vital role by providing balancing power. Therefore, it is significant to make sure the completion of ongoing pumped storage plants on time. In order to ensure $24 X 7$ power supply, reservoir-based mega PSP projects may be considered on major rivers in upstream areas.

Table 3: Status of PSP development in India

\begin{tabular}{|c|c|c|c|}
\hline Location & State Ca & Capacity (MW) & Operation in pumpedmode \\
\hline Nagarjuna Sagar & Telangana & 700 & Not working due to the construction of the Tail reservoir \\
\hline Panchet Hill & Jharkhand & 40 & Not working due to the construction of the Tail reservoir \\
\hline Sardar Sarovar & Gujarat & 1,200 & Not working due to the construction of the Tail reservoir \\
\hline Kadana & Gujarat & 240 & Not working owing to vibration problem \\
\hline \multicolumn{4}{|l|}{ Stages I and II } \\
\hline Kadamparai & Tamil Nadu & 400 & Working \\
\hline Bhira & Maharashtra & 150 & Working \\
\hline Srisailam & Telangana & 900 & Working \\
\hline Paithon & Maharashtra & 12 & Working \\
\hline Ujjani & Maharashtra & 12 & Working \\
\hline ^Purulia & West Bengal & 900 & Working \\
\hline *Ghatgar & Maharashtra & 250 & Working \\
\hline Total & \multicolumn{2}{|c|}{$4,804 \mathrm{MW}$} & \\
\hline \multicolumn{4}{|c|}{ Note: *These projects are pure PSPS while the remaining are of mixed type (hydropower + pumped hydro) } \\
\hline \multicolumn{4}{|c|}{ Source: Presentation by POSOCO at a recent PowerLine conference } \\
\hline
\end{tabular}




\section{B.Key issues}

In order to increase the deployment of pumped storage plants, issue of land acquisition/transfer can be solved by providing specific articles in the land acquisition Act. Another challenge pertains to obtain environment and other related clearances during the initial stage of project enactment. Such approvals are need to be provided by government bodies in a time-bound manner. During project construction, work is often disrupted due to contractual disputes and claims. This, in turn, leads to time and cost overruns. Such problems can be resolved by special task force that has powers to direct the state authorities. In order to make PSPs possible and qualify for merit order dispatch, they need to be treated as grid assets.

Table 4: PSP Potentials in India

\begin{tabular}{lcc}
\hline Region & No. of schemes & Potential (MW) \\
Northern & 7 & 13,065 \\
Western & 25 & 39,684 \\
Southern & 8 & 17,750 \\
Eastern & 6 & 9,125 \\
North Eastern & 10 & 16,900 \\
Total & $\mathbf{5 6}$ & $\mathbf{9 6 , 5 2 4}$ \\
Source: CEA & &
\end{tabular}

A considerable portion of a PSP's capital cost needs to be counted and recovered through wheeling charges. Beneficiaries who provide off-peak power will be offered peak power after accounting for losses and will have to bear the balance $20-25$ per cent of the capital cost.

\section{Conclusion}

Therefore it can be concluded that by coordinating wind and Pumped storage Power plant we can manage the shortages met by the power sector as well as can effectively use our resources instead of using hazardous conventional sources like nuclear etc.

PSP will act as a good storage system to store the excess power produced by the wind mills and other renewable sources instead of batteries.

\section{References}

https://mnre.gov.in/img/documents/uploads/file_f-1597797108502.pdf

https://en.wikipedia.org/wiki/Renewable_energy_in_India

https://cea.nic.in/reports/others/planning/resd/mom_pump_storage_plants.pdf

http://eagri.org/eagri50/AENG352/lec14.pdf

Non-conventional Energy resources by B.H. khan

https://en.wikipedia.org/wiki/Electricity_sector_in_India 